\title{
Global mean surface temperature and climate sensitivity of the EECO, PETM and latest Paleocene
}

Gordon N. Inglis ${ }^{1,2, \dagger}$, Fran Bragg ${ }^{3}$, Natalie Burls ${ }^{4}$, David Evans ${ }^{5,}$ Gavin L. Foster $^{6}$, Matt Huber $^{7}$, Daniel J. Lunt ${ }^{3}$, Nicholas Siler ${ }^{8}$, Sebastian Steinig ${ }^{3}$, Richard Wilkinson ${ }^{9}$, Eleni Anagnostou $^{10}$, Margot Cramwinckel ${ }^{11}$, Christopher J. Hollis ${ }^{12}$, Richard D. Pancost ${ }^{1}$ and Jessica E. Tierney ${ }^{13}$

1. Organic Geochemistry Unit, School of Chemistry, School of Earth Science, University of Bristol, UK

2. Cabot Institute for the Environment, University of Bristol, UK

3. School of Geographical Sciences, University of Bristol, UK

4. Department of Atmospheric, Oceanic and Earth Sciences, George Mason University, USA

5. Institute of Geosciences, Goethe University Frankfurt, Frankfurt am Main, Germany

6. School of Ocean and Earth Science, University of Southampton, UK

7. Department of Earth, Atmospheric, and Planetary Sciences, Purdue University, USA

8. College of Earth, Ocean and Atmospheric Sciences, Oregon State University, USA

9. School of Mathematics and Statistics, University of Sheffield, UK

10. GEOMAR Helmholtz Centre for Ocean Research Kiel, Germany

11. Department of Earth Sciences, Utrecht University, Netherlands

12. GNS Science, Lower Hutt, New Zealand

13. Department of Geosciences, The University of Arizona, $1040 \mathrm{E} 4^{\text {th }}$ St Tucson AZ USA † present address: School of Ocean and Earth Science, University of Southampton, UK

Corresponding author: Gordon N. Inglis

Email: gordon.inglis@soton.ac.uk.Telephone: +44 (0)1179546395 


\section{Abstract:}

Accurate estimates of past global mean surface temperature (GMST) help to contextualise future climate change and are required to estimate the sensitivity of the climate system to $\mathrm{CO}_{2}$ forcing during the geological record. GMST estimates from the latest Paleocene and early Eocene ( $\sim 57$ to 48 million years ago) span a wide range $\left(\sim 9\right.$ to $23^{\circ} \mathrm{C}$ higher than pre-industrial) and prevent an accurate assessment of climate sensitivity during this extreme greenhouse climate interval. Here, we develop a multi-method experimental framework to calculate GMST during three target intervals: 1) the latest Paleocene ( 57 Ma), 2) the Paleocene-Eocene Thermal Maximum (56 Ma) and 3) the early Eocene Climatic Optimum (EECO; 49.4 to 53.3 Ma). Using six independent methodologies, we find that average GMST estimates during the latest Paleocene and PETM are $11.7^{\circ} \mathrm{C}\left( \pm 0.6^{\circ} \mathrm{C}\right)$ and $18.7^{\circ} \mathrm{C}\left( \pm 0.8^{\circ} \mathrm{C}\right)$ higher than preindustrial, respectively. GMST estimates from the EECO are $13.3^{\circ} \mathrm{C}\left( \pm 0.5^{\circ} \mathrm{C}\right)$ warmer than pre-industrial and comparable to previous IPCC AR5 estimates $\left(12.7^{\circ} \mathrm{C}\right.$ higher than preindustrial). Leveraging the extremely large 'signal' associated with these extreme warm climates, we combine estimates of GMST and $\mathrm{CO}_{2}$ from the latest Paleocene, PETM and EECO to calculate a gross estimate of the average climate sensitivity between the early Paleogene and today. This yields gross climate sensitivity estimates for the latest Paleocene, PETM and EECO which range between 2.8 to $4.8^{\circ} \mathrm{C}(66 \%$ confidence). These largely fall within the range predicted by the IPCC $\left(1.5\right.$ to $4.5^{\circ} \mathrm{C}$ per doubling $\left.\mathrm{CO}_{2}\right)$, but appear incompatible with low values (between 1.5 and $2.8^{\circ} \mathrm{C}$ per doubling $\mathrm{CO}_{2}$ ). 


\section{Introduction}

Under high growth and low mitigation scenarios, atmospheric carbon dioxide $\left(\mathrm{CO}_{2}\right)$ could exceed 1000 parts per million (ppm) by the year 2100 (Stocker et al., 2013). The long-term response of the Earth System under such elevated $\mathrm{CO}_{2}$ concentrations remains uncertain (Stevens et al., 2016;Knutti et al., 2017;Hegerl et al., 2007). One way to better constrain these climate predictions is to examine intervals in the geological past during which greenhouse gas levels were similar to those predicted under future scenarios. This is the rationale behind the Deep-time Model Intercomparison Project (DeepMIP) which aims to investigate the behaviour of the Earth System in three high $\mathrm{CO}_{2}$ climate states in the latest Paleocene and early Eocene ( 57-48 Ma) (Lunt et al., 2017; Hollis et al., 2019).

Sea surface temperature (SST) and land air temperature (LAT) proxies indicate that the latest Paleocene and early Eocene were characterised by global mean surface temperatures (GMST) much warmer than those of today (Cramwinckel et al., 2018;Farnsworth et al., 2019; Hansen et al., 2013;Zhu et al., 2019;Caballero and Huber, 2013). Having a robust quantitative estimate of the magnitude of warming relative to modern is useful for two primary reasons: (1) it allows us to contextualise future climate change predictions by comparing the magnitude of future anthropogenic warming with the magnitude of past natural warming; (2) combined with $\mathrm{CO}_{2}$ proxy data, it allows us to estimate climate sensitivity, a key metric for understanding how the climate system responds to $\mathrm{CO}_{2}$ forcing. The Fifth IPCC Assessment Report stated that GMST was $9^{\circ} \mathrm{C}$ to $14^{\circ} \mathrm{C}$ higher than for pre-industrial conditions during the early Eocene ( 52 to $50 \mathrm{Ma})$ (Masson-Delmotte et al., 2014). Subsequent studies indicate a wider range of estimates, from 9 to $23^{\circ} \mathrm{C}$ warmer than pre-industrial (Cramwinckel et al., 2018;Farnsworth et al., 2019;Hansen et al., 2013;Zhu et al., 2019;Caballero and Huber, 2013) (Figure 1). It is an open question whether this range arises from inconsistencies between the methods used to estimate GMST, such as selection of proxy datasets, treatment of uncertainty, and/ analysis of different time intervals. This has thwarted a robust assessment of GMST estimates for the latest Paleocene and early Eocene. 
Here we calculate GMST estimates within a consistent experimental framework for the target intervals outlined by the Deep-time Model Intercomparison Project (DeepMIP): i) the Early Eocene Climatic Optimum (EECO; 53.3 to $49.4 \mathrm{Ma}$ ), ii) the Paleocene-Eocene Thermal Maximum (PETM, ca. $56 \mathrm{Ma}$ ) and iii) the latest Paleocene (LP, ca. 57-56 Ma). We use six independent methods to obtain new GMST estimates for these three time periods, employing recently compiled datasets of SST and LAT estimates (Hollis et al., 2019) and BWT estimates (Cramer et al., 2009;Westerhold et al., 2018;Barnet et al., 2019). We also undertake a suite of additional sensitivity studies to explore the influence of particular proxies on each GMST estimate. We then combine GMST estimates from all six methods to generate a "best estimate" GMST for each time slice and use these, with existing estimates of $\mathrm{CO}_{2}$ (Gutjahr et al., 2017;Anagnostou et al., 2016) to develop new estimates of ECS during the latest Paleocene, PETM and EECO.

\section{Methods and Materials}

Three different input datasets are used to calculate GMST. Dataset $D_{\text {surf }}$ consists of surface temperature estimates. Dataset $D_{\text {deep }}$ consists of deep-water temperature estimates. Dataset $D_{\text {comb }}$ consists of a combination of surface- and deep-water temperature estimates. Six different methodologies make use of these datasets to estimate GMST. Below we describe these datasets and methods.

\subsection{Dataset $D_{\text {surf }}$}

Dataset $D_{\text {surf }}$ is version 0.1 of the DeepMIP database, as described in Hollis et al (2019). It consists of SSTs and LATs for the latest Paleocene, PETM and EECO. The SSTs are from multiple proxies, including foraminiferal $\delta^{18} \mathrm{O}$, foraminiferal $\mathrm{Mg} / \mathrm{Ca}$, clumped isotopes $(\Delta 47)$, and TEX $\mathrm{X}_{86}$. Foraminiferal $\delta^{18} \mathrm{O}$ values are calibrated to SST following Bemis et al. (1998). Foraminiferal $\mathrm{Mg} / \mathrm{Ca}$ are calibrated to SST following Evans et al. (2018). TEX 86 values are 
calibrated to SST using BAYSPAR (Tierney and Tingley, 2014). $\Delta 47$ values are reported using the parameters and calibrations of the original publications (Evans et al., 2018;Keating-Bitonti et al., 2011). LATs are derived from leaf fossils, pollen assemblages, mammal $\delta^{18} \mathrm{O}$, paleosol $\delta^{18} \mathrm{O}$ and branched GDGTs. LAT estimates are calculated using the parameters and calibrations of the original publication (see Hollis et al., 2019 and ref. therein). The location of the proxies is shown in Figure 2. For each site, we utilise the uncertainty range reported in Hollis et al. (2019). We do not explore calibration uncertainty, but instead focus on the methodologies used to calculate GMST.

Four methods ( $D_{\text {surf }}-1, D_{\text {surf }}-2, D_{\text {surt }}-3$ and $\left.D_{\text {surf }}-4\right)$ are employed to calculate GMST from dataset $D_{\text {surf. }}$ These methods employ parametric $\left(D_{\text {surf }}-1, D_{\text {surt }}-2, D_{\text {surf }}-4\right)$ or non-parametric $\left(D_{\text {surf }}-3\right)$ functions to estimate temperature. Each method conducts a 'baseline' calculation which uses the SST and LAT data compiled in accordance with the DeepMIP protocols (i.e. Hollis et al., 2019). Our baseline calculation ( $D_{\text {surf }}$ default) excludes $\delta^{18} \mathrm{O}$ values from recrystallized planktonic foraminifera as these estimates are significantly cooler than estimates derived from the $\delta^{18} \mathrm{O}$ value of well-preserved foraminifera, foraminiferal $\mathrm{Mg} / \mathrm{Ca}$ ratios and clumped isotope values from larger benthic foraminifera (see Hollis et al., 2019 and ref. therein). For each method, we also conduct a series of sub-sampling calculations, based on varying assumptions about the robustness of different proxies (Table 1). The first sensitivity experiment ( $D_{\text {surf }}$ Frosty) includes $\delta^{18} \mathrm{O}$ values from recrystallized planktonic foraminifera. The second sensitivity experiment $\left(D_{\text {surf-NoTEX) removes }}\right.$ TEX 86 values as these give slightly higher SSTs than other proxies, especially in the mid-to-high latitudes (Bijl et al., 2009;Hollis et al., 2012; Inglis et al., 2015). The third sensitivity experiment ( $D_{\text {sur-NoMBT) removes }}$ MBT(')/CBT values derived from marine sediment archives as they may suffer from a cool bias (Inglis et al., 2017;Hollis et al., 2019). The fourth sensitivity experiment ( $D_{\text {surf-NoMammal) }}$ removes mammal and paleosol $\delta^{18} \mathrm{O}$ values as these proxies may suffer from a cool bias (Hollis et al., 2019). For each method, GMST is calculated for: i) the Early Eocene Climatic 
Optimum (EECO; 53.3 to $49.4 \mathrm{Ma}$ ), ii) the Paleocene-Eocene Thermal Maximum (ca. $56 \mathrm{Ma}$ ) and iii) the latest Paleocene (LP; ca. 57-56 Ma).

\subsection{1. $D_{\text {surf }}-1$}

Method $D_{\text {surf }}-1$ was first employed by Caballero and Huber (2013) to estimate GMST from early Eocene surface temperature proxies in the era after pervasive recrystallization of foraminiferal $\delta^{18} \mathrm{O}$ values was recognized (e.g. Pearson et al., 2001;Pearson et al., 2007). This study used data compilations which were the predecessors to the DeepMIP compilation (Huber and Caballero, 2011, Hollis et al., 2012).

Here, the anomalies of individual proxy temperature data points with respect to modern values at the corresponding paleolocation are first calculated. The calculation involves binning into low, mid, and high latitudes $\left(30^{\circ} \mathrm{N}\right.$ to $30^{\circ} \mathrm{S}, 30^{\circ} \mathrm{N} / \mathrm{S}$ to $60^{\circ} \mathrm{N} / \mathrm{S}$, and $60^{\circ} \mathrm{N} / \mathrm{S}$ to $\left.90^{\circ} \mathrm{N} / \mathrm{S}\right)$, and calculating the unweighted mean anomaly within these bins between the median reconstructed value at a given locality and the temperature at the same location today (from reanalysis). The geographically binned means are then weighted according to relative spherical area to calculate a globally weighted mean temperature anomaly between the paleotime slice and modern. All samples are treated equally and considered independent. The associated errors are added in quadrature with the inter-sample standard deviation. These two sources of error were combined and normalized by the square root of the number of samples. This method is intended as an unsophisticated, brute force approach to estimating GMST when dealing with many localities with poorly characterized errors in which there is a large difference between the reconstructed temperature at a given location and the modern equivalent. It is not intended to ferret out small differences in GMST nor is it expected to work well under conditions in which temperature gradients are stronger than today, continents are far removed from their current configuration, or in situations in which systematic errors are not readily mitigated by large sample size (i.e. when there are correlations in systematic errors 
between proxies). It is designed to be relatively straightforward to interpret and simple to reproduce without relying overly on climate models or sophisticated statistical models.

Various sanity checks are performed along the way to determine if the method is likely to produce useful results for a given sampling distribution and what corrections should be applied to optimize it. For example, if we sampled the modern temperature field using a geographic sampling distribution for a given time interval, what would the reconstructed modern temperature be? If we sampled the modern global, annual average surface temperature field in the reanalysis product ERA-5 (mean value: $15.1^{\circ} \mathrm{C}$ ) with the geographic distribution of samples we have in the past, we obtain values of $16.9^{\circ} \mathrm{C}\left( \pm 1.5^{\circ} \mathrm{C}\right)$ in the latest Paleocene, $14.2^{\circ} \mathrm{C}\left( \pm 1.7^{\circ} \mathrm{C}\right)$ for the PETM, and $15.2^{\circ} \mathrm{C}\left( \pm 1.1^{\circ} \mathrm{C}\right)$ for EECO at the distribution of localities. For the sampling densities and spatial structure of the latest Paleocene and early Eocene, this method can approach the true value within $\sim 1.5^{\circ} \mathrm{C}$ and the error propagation adequately characterizes the error, in this 'perfect knowledge' scenario. Seeking precision beyond that range is probably unwarranted. However, estimating the latest Paleocene and early Eocene GMST may be somewhat easier than estimating the modern GMST because temperature gradients are roughly half modern values or less, thus spatial heterogeneity is much reduced. Indeed, in the limit of a completely flat temperature gradient, only one perfect sample would be required to estimate GSMT.

We can use paleoclimate model results to characterise how well the existing palaeographic sampling network will impact results. For the latest Paleocene, the reconstructed $\mathrm{GMST}$ is $24.6^{\circ} \mathrm{C}\left( \pm 1.3^{\circ} \mathrm{C}\right)$, compared to the true paleoclimate model mean of $25.8^{\circ} \mathrm{C}$. For the PETM, the reconstructed GMST is $27.2^{\circ} \mathrm{C}\left( \pm 1.5^{\circ} \mathrm{C}\right)$, compared to the true paleoclimate model mean of $29.3^{\circ} \mathrm{C}$. For the EECO, the reconstructed GMST is $25.3^{\circ} \mathrm{C}$ $\left( \pm 0.7^{\circ} \mathrm{C}\right)$, compared to the true paleoclimate model mean of $25.8^{\circ} \mathrm{C}$. This method produces estimates that are within random error given otherwise perfect knowledge. It is also clear that systematic errors introduced by limited paleogeographic sampling can be alleviated by incorporating the systematic offset in mean values between the true paleoclimate model GMST and the sampled paleoclimate model GMST. This is the only component in which 
paleoclimate model information is included and we utilise this offset to correct for systematic errors. While this approach could be applied uncritically, it is best applied only within the context of studying the random and systematic error structure as described above and caution should be taken in using systematic corrections that are significantly bigger than the estimated random error.

The calculations shown here utilize two utilize two CESM1 simulations, as described in Cramwinckel et al., (2018; EO3 and EO4). The two cases are chosen to minimize the magnitude of the correction to GMST and the final result is not sensitivite to the choice of reference simulation among these two. The magnitude of the global correction could be sensitive to both using different models or boundary conditions.

\subsection{2. $D_{\text {surf }}-2$}

In this method, GMST estimates are calculated using the method described in Farnsworth et al. (2019) where a transfer-function is used to calculate global mean temperature from local proxy temperatures. The transfer function is generated from a pair of Eocene climate model simulations, carried out at two $\mathrm{CO}_{2}$ concentrations. The first simulations are the same $2 \times \mathrm{CO}_{2}$ and $4 \mathrm{x} \mathrm{CO} \mathrm{CO}_{2} \mathrm{HadCM} 3 \mathrm{~L}$ Eocene simulations from Farnsworth et al (2019). The second simulations are the $\times 4 \mathrm{CO}_{2}$ and $8 \times \mathrm{CO}_{2} \mathrm{CCSM} 3$ simulations of Huber and Caballero (2011), also discussed in Lunt et al (2012). We then provide a final estimate based on each of our two models. The two models are configured for the Eocene with different paleogeographies.

The principal assumption of this approach is that global temperatures scale linearly with local temperatures, and that a climate model can represent this scaling correctly. The resulting GMST estimate is independent of the climate sensitivity of the model but is dependent on the modelled spatial distribution of temperature. For a single given proxy location with a local temperature estimate ( $\left.T^{\text {proxy }}\right)$ we estimate global GMST $\left.(<\rangle^{\text {inferred }}\right)$ as: 


$$
<\mathrm{T}^{\text {inferred }}=<T^{\text {low }}>+\left(T^{\text {proxy }}-T^{\text {low }}\right) \frac{<T^{\text {high }}>-<T^{\text {low }}}{T^{\text {high }}-T^{\text {low }}}
$$

where $\left\langle T^{\text {low }}>\right.$ and $<T^{\text {high }}>$ are the global means of a low- and high- $\mathrm{CO}_{2}$ model simulation respectively, and $T^{\text {low }}$ and $T^{\text {high }}$ are the local temperatures (same location as the proxy) from the same simulations. $T^{\text {tow }}$ and $T^{\text {high }}$ represent local modelled SSTs or local modelled nearsurface LATs (in contrast to Farnsworth et al. 2019 who only used local modelled near-surface LATs to calculate $T^{\text {low }}$ and $T^{\text {high }}$, even if $T^{\text {proxy }}$ was SST). If the proxy temperature is greater than $T^{\text {tigh }}$ or cooler than $T^{\text {tow }}$, then the inferred global mean is found by extrapolation rather than by interpolation and is therefore more uncertain (Figure 3). We repeat this process for each proxy data point (Figure 4$)$ and take an average ( \pm standard error) as our best estimate of global mean temperature.

\subsection{3. $D_{\text {surf }}$-3}

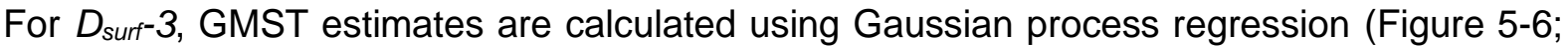
Bragg et al., Submitted). In this method, temperature is treated as an unknown function of location, $f(x)$. There are many possible functions that can fit the available proxy dataset. By using a Gaussian process model of the unknown function, we assume that temperature is a continuous and smoothly varying function of location, and once fitted to the data, the posterior mean of the model gives the most likely function form for the temperature. We use a Gaussian process prior and update it using the proxy data to obtain the posterior model which we can then use to predict the surface temperatures on a global grid. Prior specification of the model is via a mean function $E(f(x))=m(x)$, and a covariance function $\operatorname{Cov}\left(f(x), f\left(x^{\prime}\right)\right)=k\left(x, x^{\prime}\right)$ (which tells us how correlated $f(x)$ is with $\left.f\left(x^{\prime}\right)\right)$. We also specify the standard deviation of the observation uncertainty about each data point $\left(\sigma_{i}^{2}\right)$. If $\boldsymbol{f}=\left(f\left(x_{1}\right), \ldots f\left(x_{n}\right)\right)^{T}$ is a vector of temperature observations at each location $x_{-} i$, then the model is: 


$$
\boldsymbol{f} \sim \mathcal{N}(\mu, \Sigma)
$$

where $\mu_{i}=m\left(x_{i}\right)$ and $\Sigma_{i j}=k\left(x_{i}, x_{j}\right)+\mathbb{I}_{i=j} \sigma_{i}^{2}$. The proxy temperatures are expressed as anomalies to the present-day zonal mean temperature at the respective paleolatitude. We subtract the mean temperature anomaly for each time period and core experiment prior to the analysis and therefore fit the model to the residuals, using a zero-mean prior function. This means the predicted field will relax towards the mean surface warming in areas of no data coverage. The covariance function - which considers the clustering of proxy locations describes the correlation between $f\left(x_{i}\right)$ and $f\left(x_{j}\right)$ in relation to the distance of $x_{i}$ and $x_{j}$. We use a squared-exponential covariance function with Haversine distances replacing Euclidean distances so that correlation is a function of distance on the sphere. A heteroscedastic noise model is used to weight the influence of individual proxy data by their associated uncertainty, i.e. the model will better fit reconstructions with a smaller reported error.

Proxy uncertainties are taken from Hollis et al., (2019) or are set to the average of the respective proxy method where no errors were reported. Standard deviations for TEX $\mathrm{X}_{86}$ and $\mathrm{Mg} / \mathrm{Ca}$ records are derived from the reported $90 \%$ confidence intervals. A minimum value of $2.5^{\circ} \mathrm{C}$ for the standard deviation is assumed for all other methods. The output variances of the covariance function are estimated using their maximum likelihood values, obtained with the GPy Python package (GPy, 2012). Note that the Gaussian process approach provides probabilistic predictions of temperature values, i.e., uncertainty estimates of the predicted field. We apply the method to the marine and terrestrial data separately and combine the masked fields afterwards in order to prevent mutual interference. The uncertainty reported for an individual GMST estimate is the standard deviation.

Model uncertainty (expressed as standard deviation fields) is typically highest in areas with sparse data coverage (e.g. the Pacific Ocean and Southern Hemisphere land masses; Figure S1) and the lower uncertainty for the latest Paleocene relative to the PETM and EECO is partly related to the smaller reported uncertainties in the training data rather than enhanced 
data coverage. The large spread in reconstructed terrestrial temperatures for North America during the PETM (Figure S1d) and EECO (Figure Sf) also increases uncertainties for other continental areas during both time intervals.

\subsection{4. $D_{\text {surf }}-4$}

For $D_{\text {surf }}-4$, GMST estimates are calculated using a simple mathematical model, tuned to best fit the proxy data:

$$
T(\theta) \approx a+b \theta+c \cos \theta
$$

where $T(\theta)$ is the Eocene zonal-mean temperature, and the coefficients $a, b$, and $c$ are chosen to minimize the sum of the squared residuals relative to $D_{\text {surf }}$ (i.e. the SST and LAT data from Hollis et al. 2019). This model accurately represents $T(\theta)$ in the modern climate (Figure S2) when supplied with similar number of data points as are in the Hollis et al (2019) dataset, and it ensures a global solution that is consistent with the physical expectation that temperature should decrease - and the meridional gradient in temperature should increase - from the tropics toward the poles (Figure S2).

For each data point, we account for three types of uncertainty (i.e. temperature, elevation, latitude). For temperature, we assume a skew-normal probability distribution based on the stated $90 \%$ confidence intervals. Where uncertainty estimates are not given, we assume a (symmetric) normal distribution with a $90 \%$ confidence interval of $\pm 5 \mathrm{~K}$. For elevation, we assume a skew-normal distribution with a $90 \%$ confidence interval equal to the lowest and highest elevations of adjacent grid points in the paleotopography data set of Herold et al. (2014), with a lower bound of zero. For latitude, we assume a uniform distribution spanning the stated paleomagnetic and mantle estimates. 
To estimate $T(\theta)$, we randomly sample temperature, elevation, and latitude from their respective distributions at each location (Figure S3), and apply a lapse-rate adjustment of $6^{\circ} \mathrm{K} / \mathrm{km}$. Then, using a standard Monte Carlo bootstrapping method, we resample the same number of data points with replacement, and find the coefficients in Equation 3 that best fit the sub-sampled data. We repeat this procedure 10,000 times to find a probability distribution of $T(\theta)$. The uncertainty associated with an individual GMST estimate is the standard deviation.

\subsection{Dataset $D_{\text {deep }}$}

Dataset $D_{\text {deep }}$ consists of bottom water temperatures (BWTs) for the latest Paleocene, PETM and EECO. Benthic foraminifera $\delta^{18} \mathrm{O}$ values for the latest Paleocene, PETM and EECO come from previous compilations (Westerhold et al., 2018;Barnet et al., 2019;Cramer et al., 2009), adjusted to Cibicidoides following established methods (Cramer et al., 2009), allowing temperature to be calculated using Eq. 9 of Marchitto et al (2014):

$$
\left(\delta_{\mathrm{cp}}-\delta_{\mathrm{sw}}+0.27\right)=-0.245 \pm 0.005 t+0.0011 \pm 0.0002 t^{2}+3.58 \pm 0.02
$$

where $t$ is bottom water temperature in Celsius, $\delta_{\mathrm{cp}}$ is $\delta^{18} \mathrm{O}$ of $\mathrm{CaCO}_{3}$ on the PeeDee Belemnite (PDB) scale, and $\delta_{s w}$ is $\delta^{18} \mathrm{O}$ of seawater on the Standard Mean Ocean Water (SMOW). $\delta_{\text {sw }}$ is defined in accordance with the DeepMIP protocols $(-1.00 \%$; see Hollis et al., 2019). A single method $\left(D_{\text {deep }}-1\right)$ is used to calculate GMST from $D_{\text {deep }}$ following the methodology outlined in Hansen et al. (2013). For this method, GMST is calculated for: i) the Early Eocene Climatic Optimum (EECO; 53.3 to $49.4 \mathrm{Ma}$ ), ii) the Paleocene-Eocene Thermal Maximum (ca. $56 \mathrm{Ma}$ ) and iii) the latest Paleocene (LP; ca. 57-56 Ma).

\subsection{1. $D_{\text {deep }}-1$}


For $D_{\text {deep }}-1$, GMST estimates are calculated following the method of Hansen et al. (2013), which utilises only the deep ocean benthic foraminifera $\delta^{18} \mathrm{O}$ dataset, and we refer the reader to that study for a detailed justification of the approach. Briefly, GMST is scaled directly to deep ocean temperature before the Pliocene. Specifically, $\Delta \mathrm{GMST}=\Delta \mathrm{BWT}$ prior to $\sim 5.3 \mathrm{Ma}$, where early Pliocene BWT and GMST was calculated following Eq. 3.5, 3.6, and 4.2 of Hansen et al. (2013). As such, the calculations presented here differ from those of Hansen et al. (2013) only in that we use a more recent benthic $\delta^{18} \mathrm{O}$ compilation and a different equation to convert $\delta^{18} \mathrm{O}$ to temperature in the ice-free Paleogene. For each time-slice, the reported uncertainty

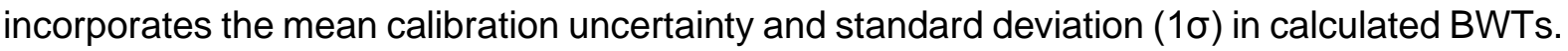

\subsection{Dataset $D_{\text {comb }}$}

Dataset $D_{\text {comb }}$ uses a combination of (tropical) surface- and deep-water temperature estimates. The deep ocean dataset $\left(D_{\text {deep }}\right)$ is identical to that described in Section 2.2. The tropical SST dataset utilises all relevant surface ocean proxy data from the DeepMIP database, i.e. those with a palaeolatitude in the magnetic reference frame within $30^{\circ}$ of the equator. An expanded definition of the tropics is used as tropical SST reconstructions are relatively sparse; $30^{\circ}$ was chosen as it retains tropical SST data from several proxies for all three intervals whilst SST seasonality remains relatively low within these latitudinal bounds.

\subsection{1. $D_{\text {comb }^{-1}}$}

For $D_{\text {comb }}-1$, GMST estimates are calculated for each time interval based on the difference between tropical SSTs and deep-ocean BWTs (Evans et al., 2018), such that:

$$
\text { GMST }=0.5(\overline{\text { troplcal SST }}+\overline{B W T})
$$


The fundamental assumptions of this approach are that: 1) GMST can be approximated by global mean SST, 2) global mean SST is equivalent to the mean of the tropical and high latitude regions, and 3) benthic temperatures are representative of high latitude surface temperatures. Applying these assumptions to the modern ocean would generate a GMST estimate within $\sim 1^{\circ} \mathrm{C}$ of measured and a modern latitudinal SST gradient within $\sim 1^{\circ} \mathrm{C}$ of the surface ocean dataset (as discussed in Evans et al., 2018).

Probability distributions for each time interval were computed as follows. In the case of the tropical SST data, 1000 subsamples were taken, following which a random normally distributed error was added to each data point in the DeepMIP compilation, including both calibration uncertainty and variance in the data where multiple reconstructions are available for a given site and time interval. Mean tropical SST was calculated for each of these subsamples. To provide a BWT dataset of the same size as the subsampled tropical SST data, 1000 normally distributed values were calculated for each time interval, based on the mean \pm 1 SD variation of the pooled benthic $\delta^{18} \mathrm{O}$ data from all sites including calibration uncertainty.

\section{Results}

\section{1. $D_{\text {surf }}-1$ to -4}

GMST estimates $\left(D_{\text {surf-default }}\right)$ during the latest Paleocene $(n=4)$ range between 25.7 and

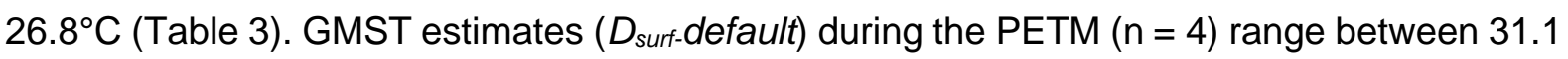
and $33.6^{\circ} \mathrm{C}$ (Table 3). GMST estimates $\left(D_{\text {surf-default }}\right)$ during the EECO $(n=4)$ range between 25.4 and $29.0^{\circ} \mathrm{C}$ (Table 3). All four methods indicate that: 1 ) the PETM is warmer than the latest Paleocene (by $\sim 4$ to $9^{\circ} \mathrm{C}$ ) and: 2 ) the PETM is warmer than the EECO (by $\sim 3$ to $7^{\circ} \mathrm{C}$ ). GMST estimates derived using $D_{\text {surf }}$ Frosty (i.e. which include planktonic foraminifera $\delta^{18} \mathrm{O}$ values) are consistently lower (up to $3.5^{\circ} \mathrm{C}$ ) than those derived using $D_{\text {surf-default. } \mathrm{GMST}}$ estimates derived using $D_{\text {surf }}$ NoTEX (i.e. which exclude TEX ${ }_{86}$ estimates) are also consistently 
lower (up to $\sim 2^{\circ} \mathrm{C}$ ) than those derived using $D_{\text {sur-default. }}$ GMST estimates derived using $D_{\text {surf }}$ NoMBT (i.e. which exclude MBT'/CBT values from marine sediments) are higher than GMST estimates derived using $D_{\text {surf-default }}$ (up to $1^{\circ} \mathrm{C}$ ). GMST estimates derived using $D_{\text {surf }}$ NoMammal (i.e. which exclude $\delta^{18} \mathrm{O}$ mammal or paleosol estimates) are similar to GMST estimates derived using $D_{\text {surf-default }}\left( \pm 0.5^{\circ} \mathrm{C}\right)$, with the exception of $D_{\text {surf }}-1$ during the EECO which is $\sim 3^{\circ} \mathrm{C}$ higher when $\delta^{18} \mathrm{O}$ mammal or paleosol values are excluded.

\section{2. $\mathrm{D}_{\text {deep }}-1$}

GMST estimates $\left(D_{\text {deep }}\right)$ during the latest Paleocene, PETM and EECO average $24.3^{\circ} \mathrm{C}$ $\left( \pm 1.8^{\circ} \mathrm{C}\right), 30.2^{\circ} \mathrm{C}\left( \pm 9.2^{\circ} \mathrm{C}\right)$ and $28.0^{\circ} \mathrm{C}\left( \pm 2.6^{\circ} \mathrm{C}\right)$, respectively (Table 3$)$. This method indicates that: 1) the PETM is warmer than the latest Paleocene (by $\sim 6^{\circ} \mathrm{C}$ ) and, 2) the PETM is warmer than the EECO $\left(\right.$ by $\left.\sim 2^{\circ} \mathrm{C}\right)$.

\section{3. $\mathrm{D}_{\mathrm{comb}}{ }^{-1}$}

GMST estimates $\left(D_{\text {comb }}\right)$ during the latest Paleocene, PETM and EECO average $21.0^{\circ} \mathrm{C}$ $\left( \pm 1.7^{\circ} \mathrm{C}\right), 26.0^{\circ} \mathrm{C}\left( \pm 5.0^{\circ} \mathrm{C}\right)$ and $22.7^{\circ} \mathrm{C}\left( \pm 2.3^{\circ} \mathrm{C}\right)$, respectively (Table 3$)$. This method indicates that: 1) the PETM is warmer than the latest Paleocene (by $\left.\sim 5^{\circ} \mathrm{C}\right)$ and, 2) the PETM is warmer than the EECO (by $\sim 3^{\circ} \mathrm{C}$ ).

\section{Discussion}

\subsection{Influence of different proxy datasets upon GMST estimates}

To explore the importance of other datasets upon our reconstructed latest Paleocene, PETM and EECO GMST estimates, we conducted a series of subsampling experiments. This was performed for methods $D_{\text {surf }}-1,-2,-3$ and -4 . In the first subsampling experiment, the inclusion of $\delta^{18} \mathrm{O}$ SST estimates from recrystallized planktonic foraminifera yields lower GMST 
estimates (ca. $\sim 1$ to $3^{\circ} \mathrm{C}$; e.g. Figure $6 \mathrm{~b}$ ). This is consistent amongst all four methods and agrees with previous studies which indicate that $\delta^{18} \mathrm{O}$ values from recrystallized planktonic foraminifera are significantly colder than estimates derived from the $\delta^{18} \mathrm{O}$ value of wellpreserved foraminifera, foraminiferal $\mathrm{Mg} / \mathrm{Ca}$ ratios and clumped isotope values from larger benthic foraminifera (Hollis et al., 2019). The removal of $\mathrm{TEX}_{86}$ also results in lower GMST estimates (ca $2-4^{\circ} \mathrm{C}$; e.g. Figure $6 \mathrm{c}$ ) across all methodologies. This is consistent with previous studies which indicate that $\mathrm{TEX}_{86}$ gives slightly higher SSTs than other proxies, especially in the mid-to-high latitudes (e.g. Hollis et al., 2012; Inglis et al. 2015). This implies that the inclusion of $\mathrm{TEX}_{86}$ may lead to a slight warm bias in GMST estimates.

The input of brGDGTs from archives other than mineral soils or peat can bias LAT estimates towards lower values (Inglis et al., 2017; Hollis et al., 2019) and the removal of MBT'/CBT-derived LAT estimates leads to a warm bias in GMST. However, excluding these proxies has a relatively minor impact on $\mathrm{GMST}\left(\sim 0.5^{\circ} \mathrm{C}\right)$. This is because in regions where MBT'/CBT values are discarded (e.g. the SW Pacific), there are other proxies (e.g. pollen assemblages, leaf floral) which yield comparable LAT estimates. The removal of $\delta^{18} \mathrm{O}$ values from paleosols or mammals also leads to a small warm bias in GMST estimates $\left(\sim 0.5^{\circ} \mathrm{C}\right)$. Intriguingly, $D_{\text {surf }}-1$ yields much higher GMST estimates $\left(\sim 3^{\circ} \mathrm{C}\right.$ higher than $D_{\text {surf }}$-default $)$ when $\delta^{18} \mathrm{O}$ values from paleosols or mammals are excluded. This is attributed to the inclusion of two "cold" LAT estimates from the Salta Basin, NW Argentina (Hyland et al., 2017) which overly influence GMST (Figure 6e; Figure 7b-c;). These estimates are derived from the salinization index (SAL) (Sheldon et al., 2002) and the paleosol weathering index (PWI) (Gallagher and Sheldon, 2013), both of which yield a cold bias in the original DeepMIP database (Hollis et al. 2019).

\subsection{Intercomparison of methods for calculating GMST}

For consistency, the following section discusses 'baseline' GMST estimates only. During the latest Paleocene and PETM, GMST estimates derived from $D_{\text {surf }}$ average $\sim 27$ and $32^{\circ} \mathrm{C}$, 
respectively (Figure 8). These values agree with previous studies analysing the latest Paleocene ( $27^{\circ} \mathrm{C}$; Zhu et al., 2019) and PETM ( 32 ${ }^{\circ} \mathrm{C}$; Zhu et al., 2019). During the EECO, GMST estimates calculated using $D_{\text {surf }}$ range between $\sim 25$ and $28^{\circ} \mathrm{C}$ (Figure 8 ). These values are comparable to previous estimates from similar time intervals (ca. 29 to $30^{\circ} \mathrm{C}$; Huber and Caballero, 2011; Caballero and Huber, 2013; Zhu et al., 2019), but are up to $4^{\circ} \mathrm{C}$ lower. This cooling can be attributed to two factors. Firstly, our EECO dataset is largely comprised of land air temperature proxy data ( $n=80$ LAT estimates; $n=27$ SST estimates) which can suffer from a cold bias (Hollis et al., 2019). To explore whether LAT estimates skew GMST estimates towards lower values, we derived GMST using only SST or only LAT data. This analysis was performed using $D_{\text {surf }}-1,-2$ and $D_{\text {surf }}-4$ and indicates that the GMST estimate are $\sim 2$ to $4^{\circ} \mathrm{C}$ lower when calculated using LAT proxies only. This may be less pronounced in previous studies (i.e. Zhu et al. 2019) because they utilise a different compilation with fewer LAT estimates $\left(n=51\right.$; Huber and Caballero, 2011). Secondly, the inclusion of $\delta^{18} O$ values from paleosols or mammals leads to a cold bias in GMST estimates. For $D_{\text {surf }} 1$, a direct comparison of new and prior estimates (Caballero and Huber, 2013) can be made in which the only change has been the use of a newer data compilation. For this new method (Figure 7), the EECO is $\sim 3.5^{\circ} \mathrm{C}$ colder than previous estimates $\left(29.75^{\circ} \mathrm{C}\right.$; Caballero and Huber, 2013). Given that the floristic LAT estimates are identical between the DeepMIP compilation and the older compilation, this strongly suggests that the cooling with respect to older estimates is largely due to the incorporation of paleosol temperature estimates. This suggests that more investigation of the systematic cold bias introduced by paleosols is warranted.

During the latest Paleocene, PETM and EECO, GMST estimates calculated using $D_{\text {deep }}$ average $\sim 24^{\circ} \mathrm{C}\left( \pm 1.8^{\circ} \mathrm{C}\right), \sim 30\left( \pm 9.2^{\circ} \mathrm{C}\right)$ and $\sim 28^{\circ} \mathrm{C}\left( \pm 2.6^{\circ} \mathrm{C}\right)$, respectively (Figure 8 ). These estimates are comparable to those derived via surface temperature proxies (Table 3). GMST estimates from the EECO are also comparable to previous estimates based on globally distributed benthic foraminifera data $\left(\sim 28^{\circ} \mathrm{C}\right.$; Hansen et al., 2013). This implies that benthic foraminiferal $\delta^{18} \mathrm{O}$ values could be used to provide the 'fine temporal structure' of Cenozoic 
temperature change (Lunt et al., 2016;Hansen et al., 2013). However, we also urge caution as this approach scales GMST directly to BWT prior to the Pliocene, and therefore assumes that the characteristics of polar amplification are constant through time or balanced by other processes. We also note that GMST estimates for the PETM are associated with a large uncertainty. This is due to differences in $\delta^{18} \mathrm{O}$ values between sites and an overall lack of PETM benthic data ( $n=22$ from 3 sites) rather than an inherent uncertainty in the proxy or method of calculating GMST.

During the latest Paleocene, PETM and EECO, GMST estimates calculated using $D_{\text {comb }}$ average $\sim 21^{\circ} \mathrm{C}\left( \pm 1.7^{\circ} \mathrm{C}\right), \sim 26\left( \pm 5.0^{\circ} \mathrm{C}\right)$ and $\sim 23^{\circ} \mathrm{C}\left( \pm 2.3^{\circ} \mathrm{C}\right)$, respectively (Figure 8). These estimates are consistently lower (by $\sim 2$ to $5^{\circ} \mathrm{C}$ ) than GMST estimates derived using $D_{\text {surf }}(\mathrm{n}=4)$ and $D_{\text {deep }}(\mathrm{n}=1)$. We suggest this mismatch could be related to two factors. First, if deep water formation preferentially takes place during the winter months, GMST estimates will be biased towards lower values. Secondly, there are relatively few tropical SST estimates during the EECO ( $\mathrm{n}=10$ sites), such that $D_{\text {comb }}$ may not be fully representative of actual tropical warmth.

\subsection{A 'best estimate' of GMST during the latest Paleocene, PETM and EECO}

To derive the 'best estimate' of GMST during the latest Paleocene, PETM and EECO, we combine GMST estimates from each 'baseline' experiment (except $D_{\text {surf }}-1$ for the EECO which uses $D_{\text {surf }}$ NoMammal) and calculate a weighted average (Figure 8). This approach is useful because it assigns lower confidence to GMST estimates associated with larger uncertainties (e.g. $D_{\text {deep-1 }} 1$ during the PETM). The reported uncertainty is the reciprocal square root of the sum of all the individual weights. Sequential removal of one time series at a time (jacknife resampling) was performed to examine the influence of a single method upon the average GMST estimate. Jackknifing reveals that that no single method overly influences the mean GMST during the latest Paleocene, PETM or EECO (ca. $\left.\pm 1.0^{\circ} \mathrm{C}\right)$. 
We find that the average GMST estimate for the latest Paleocene, PETM and EECO are $25.7^{\circ} \mathrm{C}\left( \pm 0.6^{\circ} \mathrm{C}\right), 32.7^{\circ} \mathrm{C}\left( \pm 0.8^{\circ} \mathrm{C}\right)$ and $27.3^{\circ} \mathrm{C}\left( \pm 0.5^{\circ} \mathrm{C}\right)$, respectively (Figure 8). Assuming a preindustrial GMST of $14^{\circ} \mathrm{C}$, our average GMST estimates indicate that the latest Paleocene, PETM and EECO are $+11.7^{\circ} \mathrm{C},+18.7^{\circ} \mathrm{C}$ and $+13.3^{\circ} \mathrm{C}$ warmer than pre-industrial, respectively. The GMST anomaly for the EECO is skewed to cooler values than previous work $\left(\sim 15^{\circ} \mathrm{C}\right.$ warmer than pre-industrial; Caballero and Huber, 2013; Zhu et al., 2019) but lies within the range quoted previously in the IPCC AR5 $\left(12.7^{\circ} \mathrm{C}\right.$ warmer than pre-industrial). On average, GMST increases by $\sim 6$ to $7^{\circ} \mathrm{C}$ between the latest Paleocene and PETM, in keeping with previous estimates (Frieling et al., 2019; Dunkley Jones, 2013). The PETM is approximately $5^{\circ} \mathrm{C}$ warmer than the EECO. This is higher than previously suggested $\left(\sim 3^{\circ} \mathrm{C}\right.$; Zhu et al., 2019) and may related to a cold bias in EECO GMST estimates (see Section 4.2).

\subsection{Equilibrium climate sensitivity during the latest Palaeocene, PETM and EECO}

Equilibrium climate sensitivity (ECS) can be defined as the equilibrium change in global near surface air temperature, resulting from a doubling in atmospheric $\mathrm{CO}_{2}$. Various "flavours" of ECS exist, some of which specifically exclude various feedback processes not always included in climate models, such as those associated with ice sheets, vegetation, or aerosols (Rohling et al., 2012). ECS may also be state-dependent (Caballero and Huber, 2013) and there is no reason to expect it has not changed with time. Therefore, direct comparison of ECS in the past to modern conditions is a fraught enterprise. For our purposes we define a 'bulk ECS' as being a gross estimate of ECS across time between our three intervals and preindustrial. Such calculations have been performed previously (Shaffer et al., 2016;Anagnostou et al., 2016) and they provide some constraint on the range of climate sensitivity values that are relevant for near-modern prediction (Rohling et al., 2012). For example, Anagnostou et al. (2016) indicated that early Eocene ECS (excluding ice sheet feedbacks) falls within the range 2.1$4.6^{\circ} \mathrm{C}$ per $\mathrm{CO}_{2}$ doubling with maximum probability for the EECO of $3.8^{\circ} \mathrm{C}$. These values $(2.1-$ $4.6^{\circ} \mathrm{C}$ per $\mathrm{CO}_{2}$ doubling) are similar to the IPCC ECS range $\left(1.5-4.5^{\circ} \mathrm{C}\right.$ at $66 \%$ confidence $)$. 
Here we calculate bulk ECS estimates using the change in GMST and $\mathrm{CO}_{2}$ in the latest Paleocene, PETM and EECO intervals with reference to the pre-industrial. Following the approach of Anagnostou et al. (2016) and using the forcing equation of Byrne and Goldblatt (2014), we first determine the relative change in climate forcing relative to pre-industrial $\left(\Delta \mathrm{F}_{\mathrm{CO} 2-}\right.$ vs-PI):

$$
\Delta \mathrm{F}_{\text {CO2-vs-PI }}=5.32 \ln \left(\mathrm{C}_{\mathrm{t}} / \mathrm{C}_{\mathrm{PI}}\right)+\left(0.39\left[\ln \left(\mathrm{C}_{\mathrm{t}} / \mathrm{C}_{\mathrm{PI}}\right)\right]^{2}\right.
$$

where $C_{P I}$ is the atmospheric $\mathrm{CO}_{2}$ concentration during pre-industrial $(278 \mathrm{ppm})$ and $C_{\mathrm{t}}$ refers to the $\mathrm{CO}_{2}$ reconstruction at a particular time in the Eocene. The mean proxy estimate of $\mathrm{CO}_{2}$ for the PETM is 2200 ppmv (+1904/-699 ppmv; Gutjahr et al., 2017). The mean proxy estimate of $\mathrm{CO}_{2}$ for the LP is $~ 870$ ppmv (Gutjahr et al., 2017; n.b. no published uncertainty available; here we assign an uncertainty of $\pm 400 \mathrm{ppm})$. The mean proxy estimate of $\mathrm{CO}_{2}$ for the EECO is 1625 ppmv ( \pm 750 ppmv) (Anagnostou et al., 2016; Hollis et al., 2019). To calculate bulk ECS, we then use radiative forcing from a doubling of $\mathrm{CO}_{2}$ from Byrne and Goldblatt (2014) to translate $\mathrm{CO}_{2}$ into forcing relative to preindustrial $\left(\Delta \mathrm{F}_{\mathrm{cO} 2}\right)$ :

$$
\mathrm{ECS}=(\Delta \mathrm{GMST}) / \Delta \mathrm{F}_{\mathrm{CO} 2-\mathrm{vs}-\mathrm{Pl}}{ }^{*} 3.875
$$

Some of the temperature anomaly of the latest Paleocene, PETM, and EECO is caused not by $\mathrm{CO}_{2}$ but by the different paleotopography, paleobathymetry, and solar constant compared with preindustrial. Furthermore, we choose here to calculate an ECS that explicitly excludes feedbacks associated with vegetation, ice sheets, and aerosols, i.e. $\mathrm{S}_{[\mathrm{CO}, \mathrm{LI}, \mathrm{VG}, \mathrm{AE}]}$ in the nomenclature of Rohling et al (2012). To account for these effects, we subtract a value of $4.5^{\circ} \mathrm{C}$ (Caballero and Huber, 2013; Zhu et al. 2019) from the GMST in Table 3. This value of $4.5^{\circ} \mathrm{C}$ is based upon a comparison of preindustrial and Eocene simulations (both $1 \times \mathrm{CO}_{2}$ ) conducted 
with CESM1.2 (Zhu et al., 2019), which incorporates the paleogeographic, solar constant, ice sheet, vegetation, aerosol, and ice sheet changes from preindustrial to Eocene. This value is similar to previous studies which attribute $\sim 4$ to $6^{\circ} \mathrm{C}$ to the non- $\mathrm{CO}_{2}$ forcings and feedbacks (Anagnostou et al., 2016; Caballero and Huber, 2013, Lunt et al., 2012). However, we note that the sensitivity to these Eocene boundary conditions is likely model-dependant and this value will likely differ between model simulations. The uncertainties in our estimated ECS are the products of 10,000 realizations of the latest Paleocene, PETM and EECO $\mathrm{CO}_{2}$ values and the respective $\triangle$ GMST estimate (the mean estimate and uncertainty in Table 3) based on randomly sampling each variable within its $95 \%$ confidence interval uncertainty envelope

We estimate $\mathrm{S}_{[\mathrm{CO}, \mathrm{LI}, \mathrm{VG}, \mathrm{AE}]}$ for the latest Paleocene, EECO and PETM to range between 0.73 and 1.12 (66\% confidence; Figure 9). This yields bulk ECS estimates for the latest Paleocene, EECO and PETM compared to modern which range between 2.8 to $4.8{ }^{\circ} \mathrm{C}$ per doubling $\mathrm{CO} 2$ (66\% confidence). These values are comparable to previous estimates from the early Eocene which also account for paleogeography and other feedbacks ( 2.1 to $4.6^{\circ} \mathrm{C}$; Anagnostou et al., 2016) and fall within the modern ECS range predicted by the IPCC (1.5 to $4.5^{\circ} \mathrm{C}$ per doubling $\mathrm{CO}_{2}$ ). However, care must be exercised when relating geological estimates to modern climate predictions (e.g. Rohling et al., 2012). In addition, published $\mathrm{CO}_{2}$ estimates remain uncertain (especially during the latest Paleocene and PETM) and new high-fidelity records are required to accurately constrain ECS during these super warm climates.

\section{Conclusions}

Using six different methods, we have quantified global mean surface temperatures (GMST) during the latest Paleocene, PETM and EECO. GMST was calculated within a coordinated, experimental framework and utilised three different input datasets. After evaluating the impact of different proxy datasets upon GMST estimates, we combined all six methodologies to derive an average GMST value during the latest Paleocene, PETM and EECO. Our results indicate high GMSTs during the latest Paleocene $\left(25.7^{\circ} \mathrm{C} \pm 0.6^{\circ} \mathrm{C}\right), \operatorname{PETM}\left(32.7^{\circ} \mathrm{C} \pm 0.8^{\circ} \mathrm{C}\right)$ and EECO 
$\left(27.3^{\circ} \mathrm{C} \pm 0.5^{\circ} \mathrm{C}\right)$. Assuming a preindustrial GMST of $14^{\circ} \mathrm{C}$, our average GMST estimates for the latest Paleocene, PETM and EECO are $11.7^{\circ} \mathrm{C}, 18.7^{\circ} \mathrm{C}$ and $13.3^{\circ} \mathrm{C}$ higher than preindustrial, respectively. Using our 'combined' GMST estimates, we then estimated a bulk ECS during the latest Paleocene, PETM and EECO. Our results range between 2.8 to $4.8^{\circ} \mathrm{C}$ (at $66 \%$ confidence) per doubling of atmospheric $\mathrm{CO}_{2}$ when feedbacks associated with ice sheets, vegetation, and aerosols are accounted for. Taken together, our study improves our characterisation of the global mean temperature of these key time periods, allowing future climate change to be put into the context of past changes, and allowing us to provide a refined estimate of ECS.

\section{Data availability}

Data can be accessed via the online supporting information, via www.pangaea.de/, or from the author (email: gordon.inglis@soton.ac.uk).

\section{Authorship tiers and contributions}

Authorship of this manuscript is organized into three tiers according to the contributions of each individual author. Inglis (Tier I) organized the structure and writing of the manuscript, contributed to all sections of the text and designed the figures. Tier II authors (listed alphabetically following Inglis) assumed a leading role by contributing methodologies used in the text. Tier III authors (listed alphabetically following Wilkinson) contributed intellectually to the text and figure design.

\section{Declaration of competing interest}

The authors declare that they have no known competing financial interests or personal relationships that could have appeared to influence the work reported in this paper. 


\section{Acknowledgements}

This research was funded from NERC through NE/P01903X/1 and NE/N006828/1, both of which supported GNI, DL, SS and RDP. GNI was also supported by a Royal Society Dorothy Hodgkin Fellowship. N.J.B. is supported by NSF AGS-1844380. FB, DL, and RDW were funded by the EPSRC 'Past Earth Network'. MH was funded by NSF OPP 1842059.

\section{References}

Anagnostou, E., John, E. H., Edgar, K. M., Foster, G. L., Ridgwell, A., Inglis, G. N., Pancost, R. D., Lunt, D. J., and Pearson, P. N.: Changing atmospheric CO2 concentration was the primary driver of early Cenozoic climate, Nature, 533, 380-384, 10.1038/nature17423, 2016.

Barnet, J. S., Littler, K., Westerhold, T., Kroon, D., Leng, M. J., Bailey, I., Röhl, U., and Zachos, J. C.: A high-Fidelity benthic stable isotope record of late Cretaceous-early Eocene climate change and carbon-cycling, Paleoceanography \& Paleoclimatology, 34, 672$691,2019$.

Bemis, B. E., Spero, H. J., Bijma, J., and Lea, D. W.: Reevaluation of the oxygen isotopic composition of planktonic foraminifera: Experimental results and revised paleotemperature equations, Paleoceanography \& Paleoclimatology, 13, 150-160, 10.1029/98pa00070, 1998.

Bijl, P. K., Schouten, S., Sluijs, A., Reichart, G.-J., Zachos, J. C., and Brinkhuis, H.: Early Palaeogene temperature evolution of the southwest Pacific Ocean, Nature, 461, 776779 , http://www.nature.com/nature/journal/v461/n7265/suppinfo/nature08399_S1.html, 2009.

Bragg, F. J., Paine, P., Saul, A., Lunt, D. J., Wilkinson, R., and Zammit-Mangion, A.: A Statistical Algorithm for Evaluating Palaeoclimate Simulations Against Geological Observations, Geoscientific Model Development, Submitted. 
Byrne, B., and Goldblatt, C.: Radiative forcing at high concentrations of well-mixed greenhouse gases, Geophysical Research Letters, 41, 152-160, 2014.

Caballero, R., and Huber, M.: State-dependent climate sensitivity in past warm climates and its implications for future climate projections, Proceedings of the National Academy of Sciences, 110, 14162-14167, 2013.

Cramer, B. S., Toggweiler, J. R., Wright, J. D., Katz, M. E., and Miller, K. G.: Ocean overturning since the Late Cretaceous: Inferences from a new benthic foraminiferal isotope compilation, Paleoceanography \& Paleoclimatology, 24, 10.1029/2008pa001683, 2009.

Cramwinckel, M. J., Huber, M., Kocken, I. J., Agnini, C., Bijl, P. K., Bohaty, S. M., Frieling, J., Goldner, A., Hilgen, F. J., Kip, E. L., Peterse, F., van der Ploeg, R., Rohl, U., Schouten, S., and Sluijs, A.: Synchronous tropical and polar temperature evolution in the Eocene, Nature, 559, 382, 2018.

Evans, D., Sagoo, N., Renema, W., Cotton, L. J., Müller, W., Todd, J. A., Saraswati, P. K., Stassen, P., Ziegler, M., Pearson, P. N., Valdes, P. J., and Affek, H. P.: Eocene greenhouse climate revealed by coupled clumped isotope- $\mathrm{Mg} / \mathrm{Ca}$ thermometry, Proceedings of the National Academy of Sciences, 115, 1174-1179, 10.1073/pnas.1714744115\%J Proceedings of the National Academy of Sciences, 2018.

Farnsworth, A., Lunt, D., O'Brien, C., Foster, G., Inglis, G., Markwick, P., Pancost, R., and Robinson, S.: Climate sensitivity on geological timescales controlled by non-linear feedbacks and ocean circulation, Geophysical Research Letters, 2019.

Gallagher, T. M., and Sheldon, N. D.: A new paleothermometer for forest paleosols and its implications for Cenozoic climate, Geology, 41, 647-650, 10.1130/G34074.1, 2013.

Gutjahr, M., Ridgwell, A., Sexton, P. F., Anagnostou, E., Pearson, P. N., Pälike, H., Norris, R. D., Thomas, E., and Foster, G. L.: Very large release of mostly volcanic carbon during the Palaeocene-Eocene Thermal Maximum, Nature, 548, 573-577, 10.1038/nature23646, 2017. 
Hansen, J., Sato, M., Russell, G., and Kharecha, P.: Climate sensitivity, sea level and atmospheric carbon dioxide, Philosophical Transactions of the Royal Society A: Mathematical, Physical Engineering Sciences, 371, 20120294, 2013.

Hegerl, G. C., Zwiers, F. W., Braconnot, P., Gillett, N. P., Luo, Y., Marengo Orsini, J., Nicholls, N., Penner, J. E., and Stott, P. A.: Understanding and attributing climate change, IPCC, 2007: Climate Change 2007: the physical science basis. contribution of Working Group I to the Fourth Assessment Report of the Intergovernmental Panel on Climate Change, 2007.

Herold, N., Buzan, J., Seton, M., Goldner, A., Green, J. A. M., Müller, R. D., Markwick, P., and Huber, M.: A suite of early Eocene ( $55 \mathrm{Ma}$ ) climate model boundary conditions, Geoscientific Model Development, 7, 2077-2090, 10.5194/gmd-7-2077-2014, 2014.

Hollis, C. J., Taylor, K. W. R., Handley, L., Pancost, R. D., Huber, M., Creech, J. B., Hines, B. R., Crouch, E. M., Morgans, H. E. G., Crampton, J. S., Gibbs, S., Pearson, P. N., and Zachos, J. C.: Early Paleogene temperature history of the Southwest Pacific Ocean: Reconciling proxies and models, Earth and Planetary Science Letters, 349-350, 5366, http://dx.doi.org/10.1016/j.epsl.2012.06.024, 2012.

Hollis, C. J., Dunkley Jones, T., Anagnostou, E., Bijl, P. K., Cramwinckel, M. J., Cui, Y., Dickens, G. R., Edgar, K. M., Eley, Y., Evans, D., Foster, G. L., Frieling, J., Inglis, G. N., Kennedy, E. M., Kozdon, R., Lauretano, V., Lear, C. H., Littler, K., Lourens, L., Meckler, A. N., Naafs, B. D. A., Pälike, H., Pancost, R. D., Pearson, P. N., Röhl, U., Royer, D. L., Salzmann, U., Schubert, B. A., Seebeck, H., Sluijs, A., Speijer, R. P., Stassen, P., Tierney, J., Tripati, A., Wade, B., Westerhold, T., Witkowski, C., Zachos, J. C., Zhang, Y. G., Huber, M., and Lunt, D. J.: The DeepMIP contribution to PMIP4: methodologies for selection, compilation and analysis of latest Paleocene and early Eocene climate proxy data, incorporating version 0.1 of the DeepMIP database, Geoscientific Model Development, 12, 3149-3206, 10.5194/gmd-12-3149-2019, 2019. Huber, M., and Caballero, R.: The early Eocene equable climate problem revisited, Clim. Past, 7, 603-633, 10.5194/cp-7-603-2011, 2011. 
Hyland, E. G., Sheldon, N. D., and Cotton, J. M.: Constraining the early Eocene climatic optimum: A terrestrial interhemispheric comparison, GSA Bulletin, 129, 244-252, 10.1130/B31493.1, 2017.

Inglis, G. N., Farnsworth, A., Lunt, D., Foster, G. L., Hollis, C. J., Pagani, M., Jardine, P. E., Pearson, P. N., Markwick, P., Galsworthy, A. M. J., Raynham, L., Taylor, K. W. R., and Pancost, R. D.: Descent toward the Icehouse: Eocene sea surface cooling inferred from GDGT distributions, Paleoceanography, 30, 1000-1020, 10.1002/2014pa002723, 2015.

Inglis, G. N., Collinson, M. E., Riegel, W., Wilde, V., Farnsworth, A., Lunt, D. J., Valdes, P., Robson, B. E., Scott, A. C., Lenz, O. K., Naafs, B. D. A., and Pancost, R. D.: Midlatitude continental temperatures through the early Eocene in western Europe, Earth and Planetary Science Letters, 460, 86-96, https://doi.org/10.1016/j.epsl.2016.12.009, 2017.

Keating-Bitonti, C. R., Ivany, L. C., Affek, H. P., Douglas, P., and Samson, S. D.: Warm, not super-hot, temperatures in the early Eocene subtropics, Geology, 39, 771-774, 2011.

Knutti, R., Rugenstein, M. A., and Hegerl, G. C.: Beyond equilibrium climate sensitivity, Nature Geoscience, 10, 727-736, 2017.

Lunt, D. J., Jones, T. D., Heinemann, M., Huber, M., LeGrande, A., Winguth, A., Loptson, C., Marotzke, J., Roberts, C., and Tindall, J.: A model-data comparison for a multi-model ensemble of early Eocene atmosphere-ocean simulations: EoMIP, Climate of the Past, 8, 2012.

Lunt, D. J., Farnsworth, A., Loptson, C., Foster, G. L., Markwick, P., O'Brien, C. L., Pancost, R. D., Robinson, S. A., and Wrobel, N.: Palaeogeographic controls on climate and proxy interpretation, Climate of the Past, 12, 1181-1198, 2016.

Lunt, D. J., Huber, M., Anagnostou, E., Baatsen, M. L. J., Caballero, R., DeConto, R., Dijkstra, H. A., Donnadieu, Y., Evans, D., Feng, R., Foster, G. L., Gasson, E., von der Heydt, A. S., Hollis, C. J., Inglis, G. N., Jones, S. M., Kiehl, J., Kirtland Turner, S., Korty, R. L., Kozdon, R., Krishnan, S., Ladant, J. B., Langebroek, P., Lear, C. H., LeGrande, A. 
N., Littler, K., Markwick, P., Otto-Bliesner, B., Pearson, P., Poulsen, C. J., Salzmann, U., Shields, C., Snell, K., Stärz, M., Super, J., Tabor, C., Tierney, J. E., Tourte, G. J. L., Tripati, A., Upchurch, G. R., Wade, B. S., Wing, S. L., Winguth, A. M. E., Wright, N. M., Zachos, J. C., and Zeebe, R. E.: The DeepMIP contribution to PMIP4: experimental design for model simulations of the EECO, PETM, and pre-PETM (version 1.0), Geoscientific Model Development, 10, 889-901, 10.5194/gmd-10-889-2017, 2017.

Marchitto, T., Curry, W., Lynch-Stieglitz, J., Bryan, S., Cobb, K., and Lund, D.: Improved oxygen isotope temperature calibrations for cosmopolitan benthic foraminifera, Geochimica et Cosmochimica Acta, 130, 1-11, 2014.

Masson-Delmotte, V., Schulz, M., Abe-Ouchi, A., Beer, J., Ganopolski, A., Gonzalez Rouco, J. F., Jansen, E., Lambeck, K., Luterbacher, J., Naish, T., Osborn, T., Otto-Bliesner, B., Quinn, T., Ramesh, R., Rojas, M., Shao, X., and Timmermann, A.: Information from Paleoclimate Archives, in: Climate Change 2013 - The Physical Science Basis: Working Group I Contribution to the Fifth Assessment Report of the Intergovernmental Panel on Climate Change, Cambridge University Press, Cambridge, 383-464, 2014.

Pearson, P. N., Ditchfield, P. W., Singano, J., Harcourt-Brown, K. G., Nicholas, C. J., Olsson, R. K., Shackleton, N. J., and Hall, M. A.: Warm tropical sea surface temperatures in the Late Cretaceous and Eocene epochs, Nature, 413, 481-487, 2001.

Pearson, P. N., van Dongen, B. E., Nicholas, C. J., Pancost, R. D., Schouten, S., Singano, J. M., and Wade, B. S.: Stable warm tropical climate through the Eocene Epoch, Geology, 35, 211-214, 10.1130/g23175a.1, 2007.

Rohling, E. J., Sluijs, A., Dijkstra, H. A., Köhler, P., van de Wal, R. S. W., von der Heydt, A. S., Beerling, D. J., Berger, A., Bijl, P. K., Crucifix, M., DeConto, R., Drijfhout, S. S., Fedorov, A., Foster, G. L., Ganopolski, A., Hansen, J., Hönisch, B., Hooghiemstra, H., Huber, M., Huybers, P., Knutti, R., Lea, D. W., Lourens, L. J., Lunt, D., MassonDelmotte, V., Medina-Elizalde, M., Otto-Bliesner, B., Pagani, M., Pälike, H., Renssen, H., Royer, D. L., Siddall, M., Valdes, P., Zachos, J. C., Zeebe, R. E., and Members, P. 
P.: Making sense of palaeoclimate sensitivity, Nature, 491, 683-691, 10.1038/nature11574, 2012.

Shaffer, G., Huber, M., Rondanelli, R., and Pedersen, J. O. P. J. G. R. L.: Deep time evidence for climate sensitivity increase with warming, 43, 6538-6545, 2016.

Sheldon, Nathan D., Retallack, Gregory J., and Tanaka, S.: Geochemical Climofunctions from North American Soils and Application to Paleosols across the Eocene-Oligocene Boundary in Oregon, The Journal of Geology, 110, 687-696, 10.1086/342865, 2002.

Stevens, B., Sherwood, S. C., Bony, S., and Webb, M. J.: Prospects for narrowing bounds on Earth's equilibrium climate sensitivity, Earth's Future, 4, 512-522, 2016.

Tierney, J. E., and Tingley, M. P.: A Bayesian, spatially-varying calibration model for the TEX86 proxy, Geochimica et Cosmochimica Acta, 127, 83-106, 2014.

Westerhold, T., Röhl, U., Donner, B., and Zachos, J. C.: Global extent of early Eocene hyperthermal events: A new Pacific benthic foraminiferal isotope record from Shatsky Rise (ODP Site 1209), Paleoceanography \& Paleoclimatology, 33, 626-642, 2018.

Zhu, J., Poulsen, C. J., and Tierney, J. E.: Simulation of Eocene extreme warmth and high climate sensitivity through cloud feedbacks, Science Advances, 5, eaax1874, 2019. 


\begin{tabular}{|c|c|c|c|c|c|}
\hline $\begin{array}{l}\text { Label } \\
\text { in Fig. } \\
1\end{array}$ & Source & $\begin{array}{l}\text { Time } \\
\text { window }\end{array}$ & $\begin{array}{l}\text { GMST } \\
\left({ }^{\circ} \mathrm{C}\right)\end{array}$ & Uncertainty & Proxy system \\
\hline $1 \mathrm{a}$ & Farnsworth et al. (2019) & $\mathrm{EE}$ & 23.4 & \pm 3.2 & $\delta^{18} \mathrm{O}$ planktonic \\
\hline $1 b$ & Farnsworth et al. (2019) & EE & 37.1 & \pm 1.4 & $\delta^{18} \mathrm{O}$ planktonic $+\mathrm{TEX}_{86}$ \\
\hline $2 a$ & Zhu et al. (2019) & LP & 27 & $\mathrm{n} / \mathrm{a}$ & Multiple \\
\hline $2 b$ & Zhu et al. (2019) & EECO & 29 & \pm 3 & Multiple \\
\hline $2 c$ & Zhu et al. (2019) & PETM & 32 & $\mathrm{n} / \mathrm{a}$ & Multiple \\
\hline 3 & Caballero and Huber (2013) & EE & 29.5 & \pm 2.6 & Multiple \\
\hline 4 & Hansen et al (2013) & EE & 28 & $\mathrm{n} / \mathrm{a}$ & $\delta^{18} \mathrm{O}$ benthic \\
\hline 5 & Cramwinckel et al. (2018) & $\mathrm{EE}$ & 29.3 & $\mathrm{n} / \mathrm{a}$ & Multiple \\
\hline
\end{tabular}

Table 1: Previous studies that have determined GMST for the early Eocene (EE), EECO, PETM or latest Paleocene (LP). n/a indicates that no error bars were reported in the original publications. 


\section{Experiment Description}

$D_{\text {surt-default }}$

All SST and LAT data compiled in Hollis et al. (2019) but excluding recrystallized planktonic foraminifera $\delta^{18} \mathrm{O}$ values

$D_{\text {surf-Frosty }} \quad D_{\text {surt-default but including recrystallized planktonic foraminifera } \delta^{18} \mathrm{O} \text { values }}$

$D_{\text {surf-NoTEX }} \quad D_{\text {surf-default but excluding TEX }}$ T6 values

$D_{\text {surf NoMBT }} \quad D_{\text {surf-default but excluding MBT(')/CBT values from marine sediments }}$

$D_{\text {surf-NoMammal }} \quad D_{\text {surf-default but excluding mammal and paleosol } \delta^{18} \mathrm{O} \text { values }}$

Table 2: Default and optional subsampling experiments applied to $D_{\text {surf }}$ 


\begin{tabular}{llllllll}
\hline \multicolumn{7}{c}{$\mathrm{GMST}\left({ }^{\circ} \mathrm{C}\right)$} \\
\hline & $\mathrm{D}_{\text {surf-1 }}$ & $\mathrm{D}_{\text {surf-2 }}$ & $\mathrm{D}_{\text {surf-3 }}$ & $\mathrm{D}_{\text {surf-4 }}$ & $\mathrm{D}_{\text {deep }}-1$ & $\mathrm{D}_{\text {comb-1 }}$ & Average \\
\hline LP & $25.9( \pm 1.0)$ & $26.8( \pm 1.2)$ & $25.7( \pm 6.0)$ & $27.6( \pm 1.3)$ & $24.3( \pm 1.1)$ & $21.0( \pm 1.7)$ & $25.7( \pm 0.6)$ \\
PETM & $33.6( \pm 1.2)$ & $33.4( \pm 1.6)$ & $31.2( \pm 7.6)$ & $31.3( \pm 1.6)$ & $30.2( \pm 9.2)$ & $26.0( \pm 5.0)$ & $32.7( \pm 0.8)$ \\
EECO & $26.3( \pm 0.7)$ & $26.7( \pm 0.9)$ & $27.9( \pm 7.0)$ & $25.4( \pm 1.1)$ & $28.0( \pm 2.6)$ & $22.7( \pm 2.3)$ & $27.3( \pm 0.5)$ \\
& & & & & & & \\
\hline
\end{tabular}

Table 3: GMST for latest Paleocene (LP), PETM and EECO. Reported GMST estimates utilise 'baseline' experiments except $D_{\text {surf }} 1$ during the EECO which uses $D_{\text {surt }}$ NoMammal. 


\begin{tabular}{lll}
\hline & ECS $\left({ }^{\circ} \mathrm{C}\right)(66 \%$ confidence $)$ & ECS $\left({ }^{\circ} \mathrm{C}\right)(95 \%$ confidence $)$ \\
\hline Latest Paleocene & $3.9-4.8$ & $3.6-5.5$ \\
PETM & $3.5-4.4$ & $3.2-5.5$ \\
EECO & $2.8-3.8$ & $2.6-5.2$ \\
\hline
\end{tabular}

Table 4: Estimates of ECS (66\% and $95 \%$ confidence) during the latest Paleocene, PETM and EECO. 


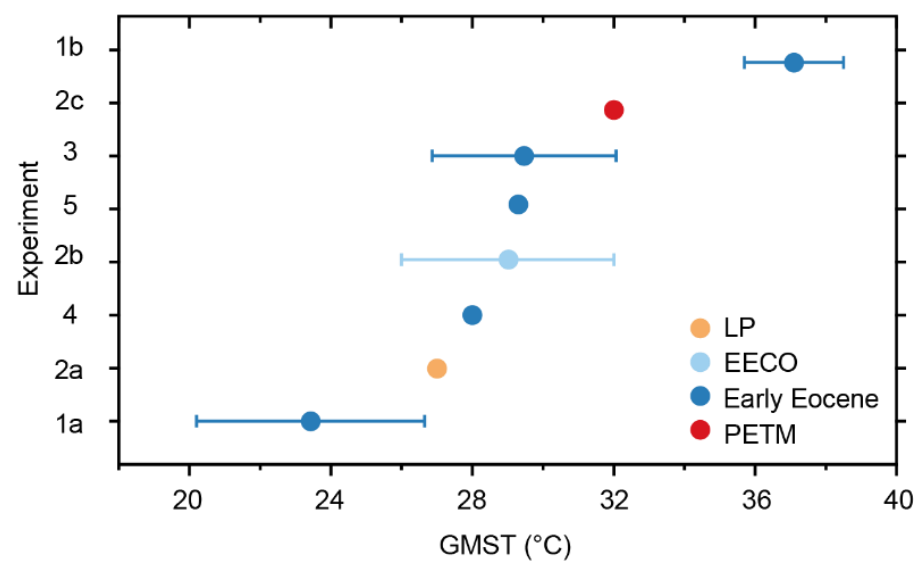

Figure 1: Published GMST estimates during the early Paleogene (57 to $48 \mathrm{Ma}$ ). Dots represent average values. The horizontal limits on the individual dots represent the reported error. $y$-Axis labels refer to previous estimates (see Table 1). 

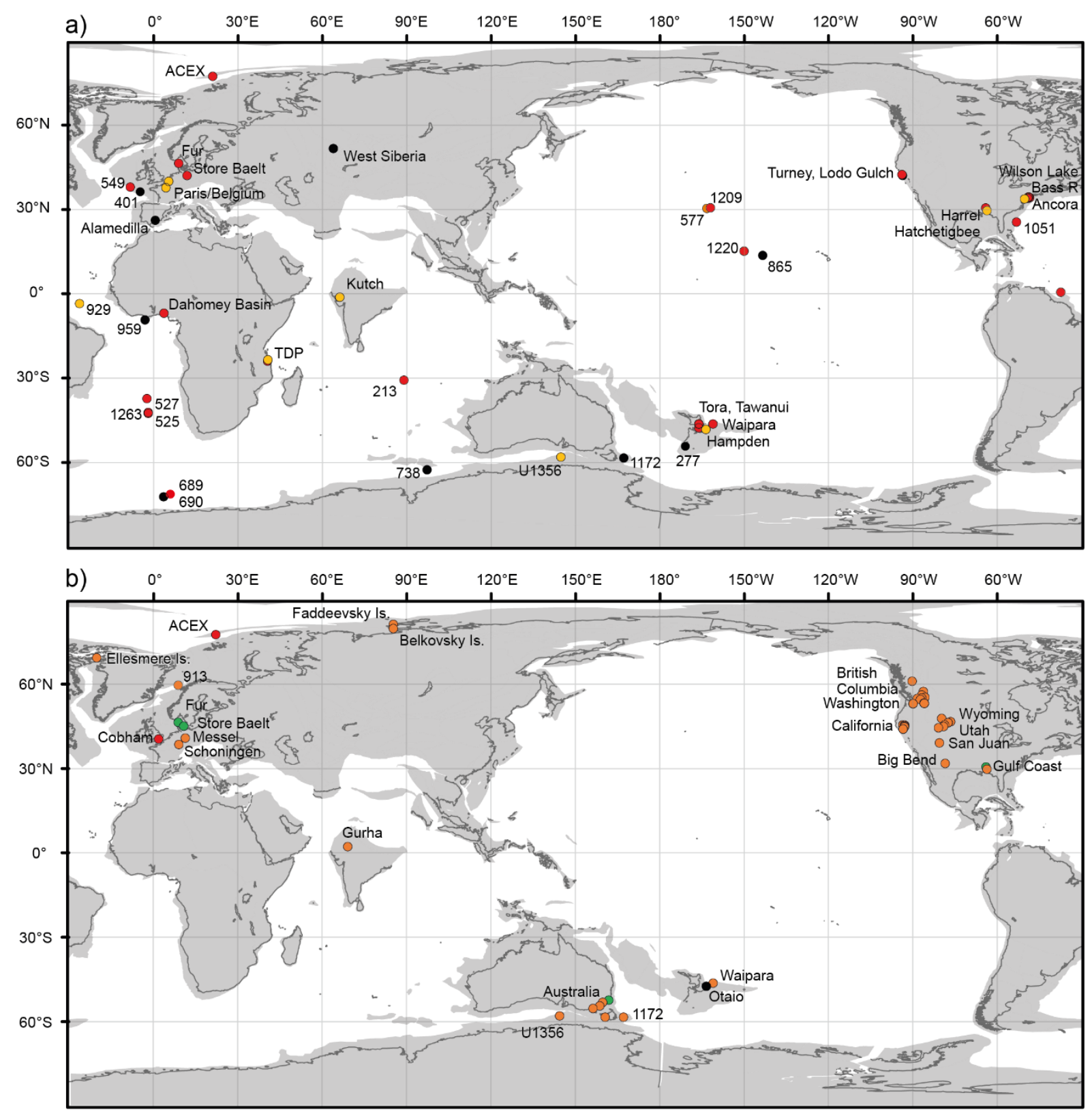

Figure 2: Location of proxies within the surface temperature dataset $\left(D_{\text {surf }}\right)$. A) SST proxies with time intervals indicated as followed: black circles, all three-time intervals represented. Red circles: PETM \pm latest Paleocene intervals; orange circles, EECO interval (b) Terrestrial sites with time intervals indicated as in (a) and green circles, LP only. 

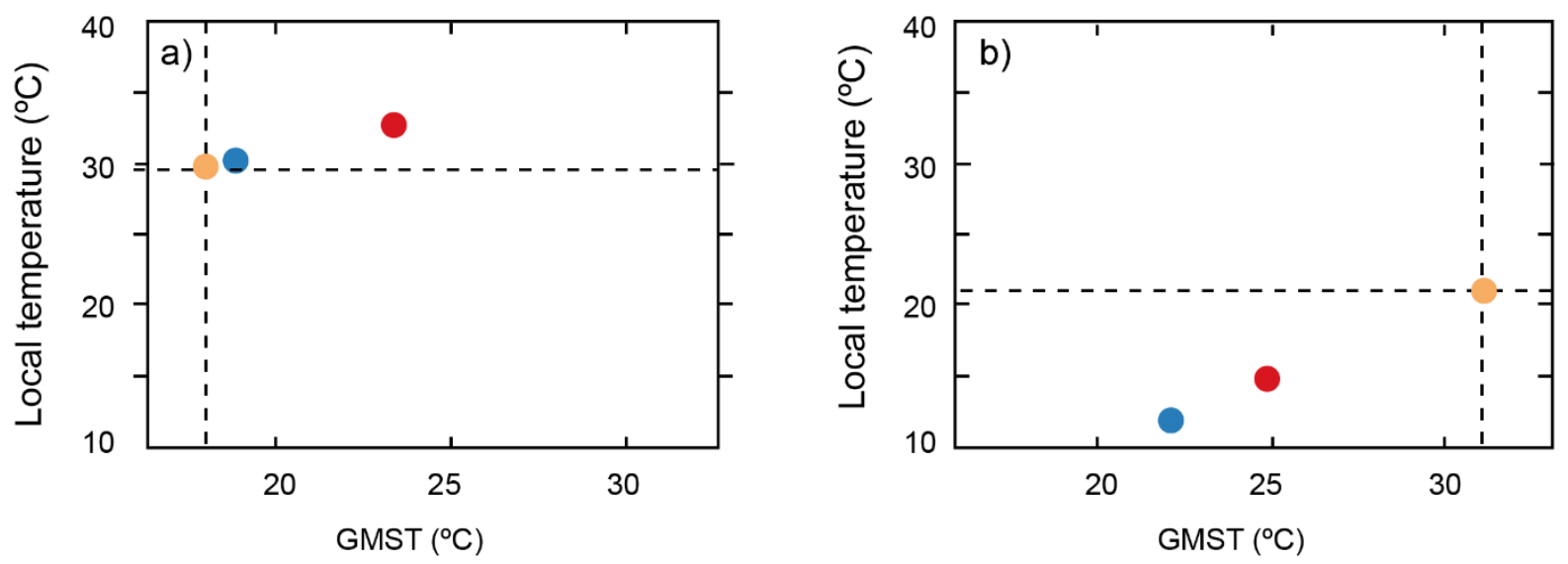

Figure 3: An illustration of Method $D_{\text {surf-2 }}$ for 2 sites: (a) Tanzania in the EECO as diagnosed using HadCM3L, and (b) Mid Waipara in the PETM as diagnosed using CCSM3. The vertical dashed line shows $<T>^{\text {inferred }}$ and the horizontal dashed line shows $T^{\text {proxy }}$, which intercept at the orange dot. The dark blue dots show the intercept of $T^{\text {low }}$ with $<T^{\text {low }}>$, and the red dots show the intercept of $T^{\text {high }}$ with $<T^{\text {high }}>$. 


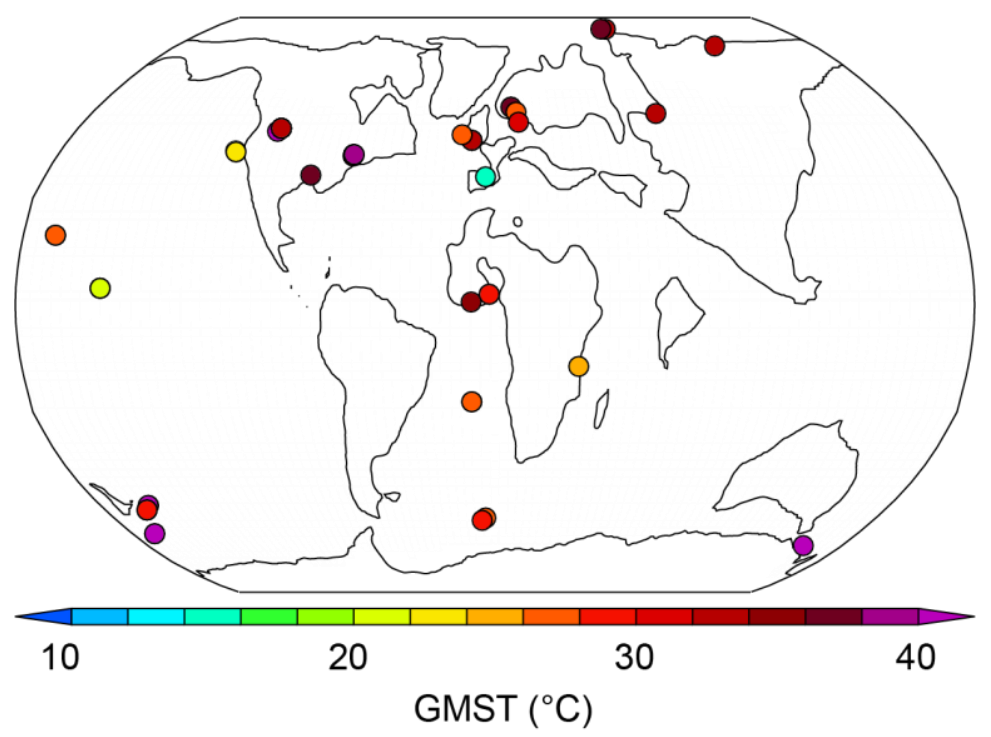

Figure 4: Inferred global mean temperature $\left(<T>^{\text {inferred }}\right)$ for each EECO-aged proxy in the DeepMIP database using $D_{\text {surf }}-2$, as diagnosed using CCSM3. The final estimate of global mean temperature is the average of all the individual sites. 


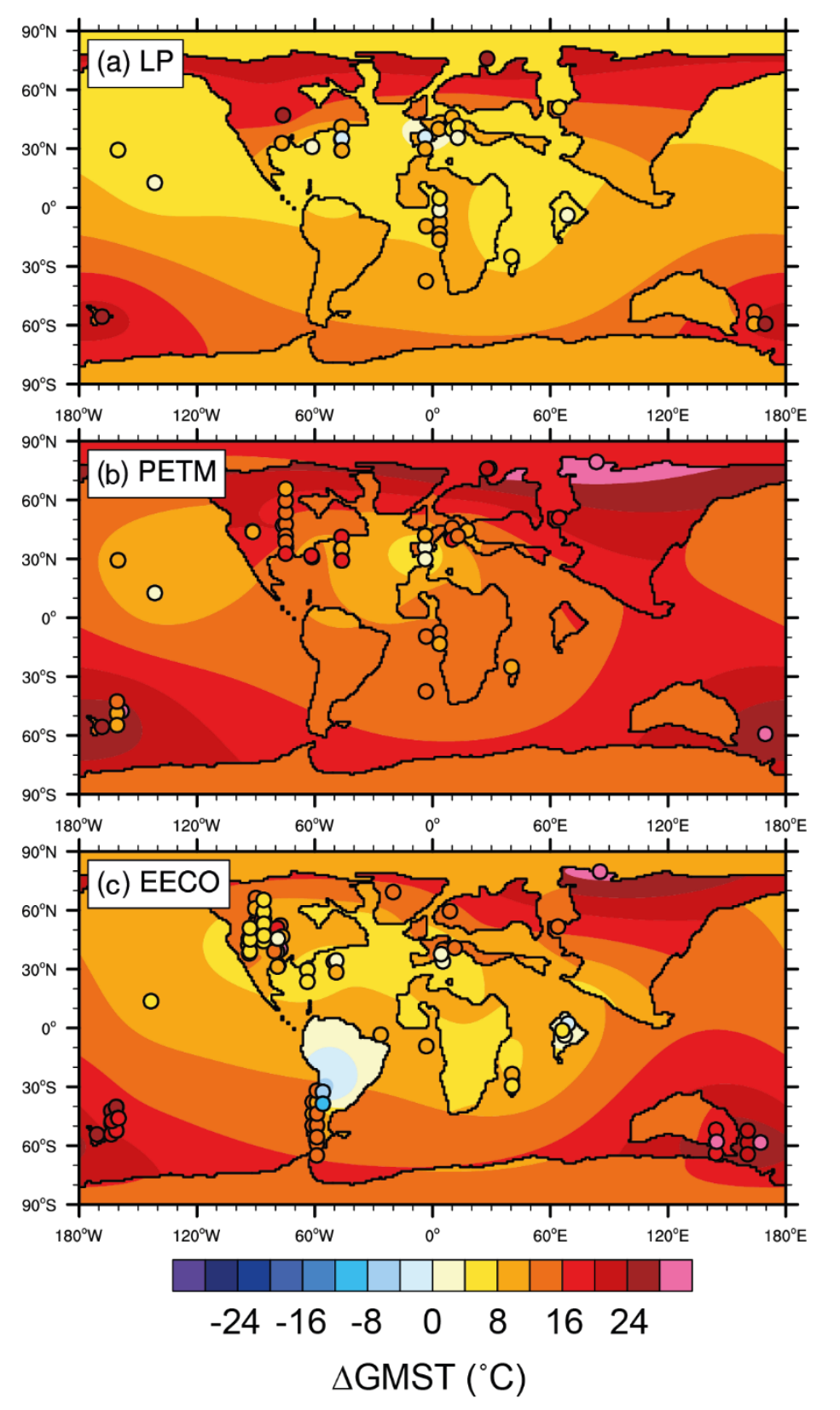

Figure 5: Predicted surface warming by Gaussian process regression using $D_{\text {surf }} 3$ for the (a) latest Paleocene, (b) PETM and (c) EECO. Anomalies are relative to the present-day zonal mean surface temperature. Circles indicate all available SST and LAT proxy data for the respective time slice that were used to train the model. Circles for locations where multiple proxy reconstructions are available are slightly shifted in latitude for improved visibility. 


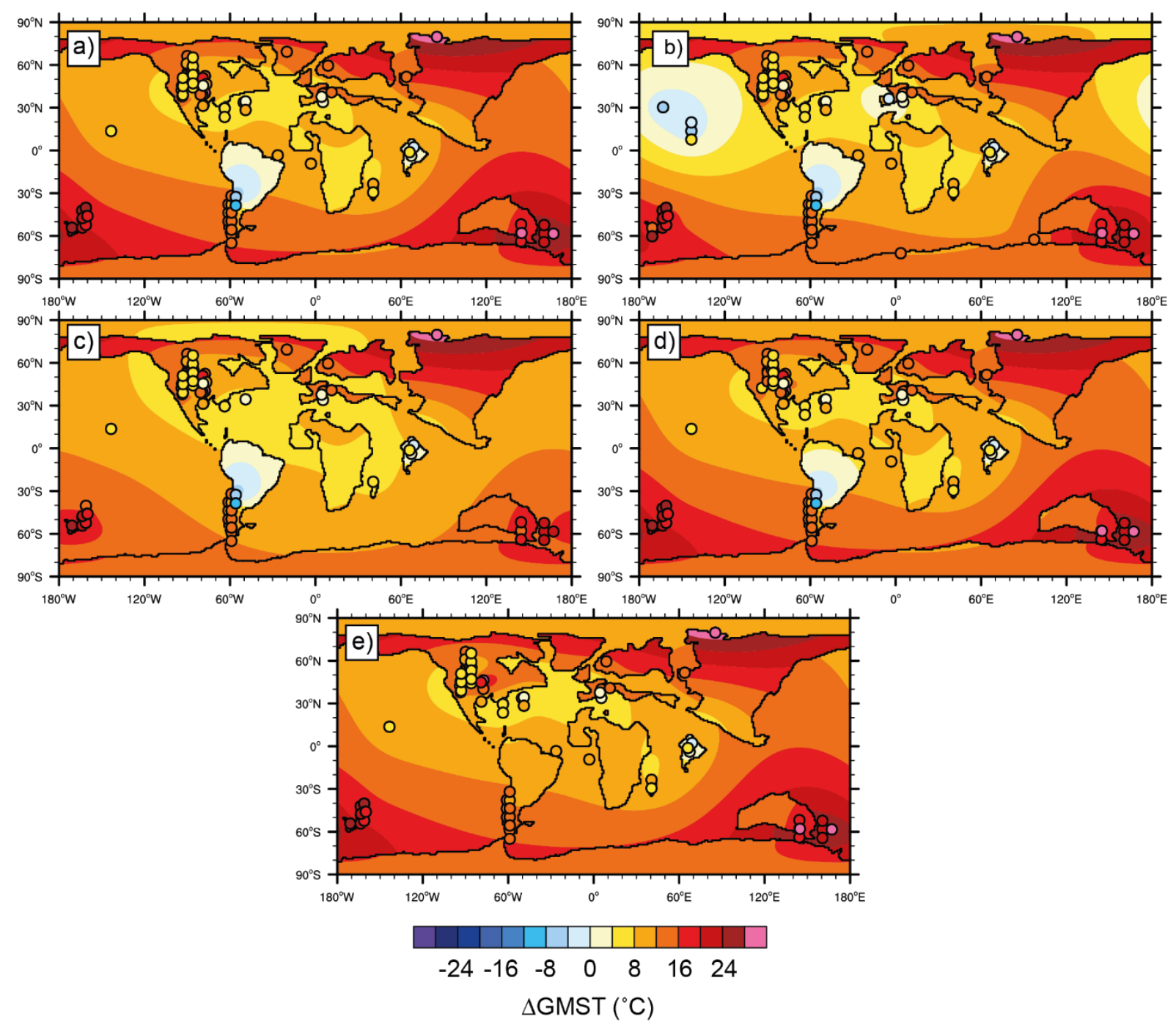

Figure 6: Predicted surface warming by Gaussian process regression using $D_{\text {surf }} 3$ for the EECO for the five core experiments (see Table 2). Anomalies are relative to the present-day zonal mean surface temperature. Circles indicate all available SST and LAT proxy data for the respective time slice and experiment that were used to train the model. Circles for locations where multiple proxy reconstructions are available are slightly shifted in latitude for improved visibility. 

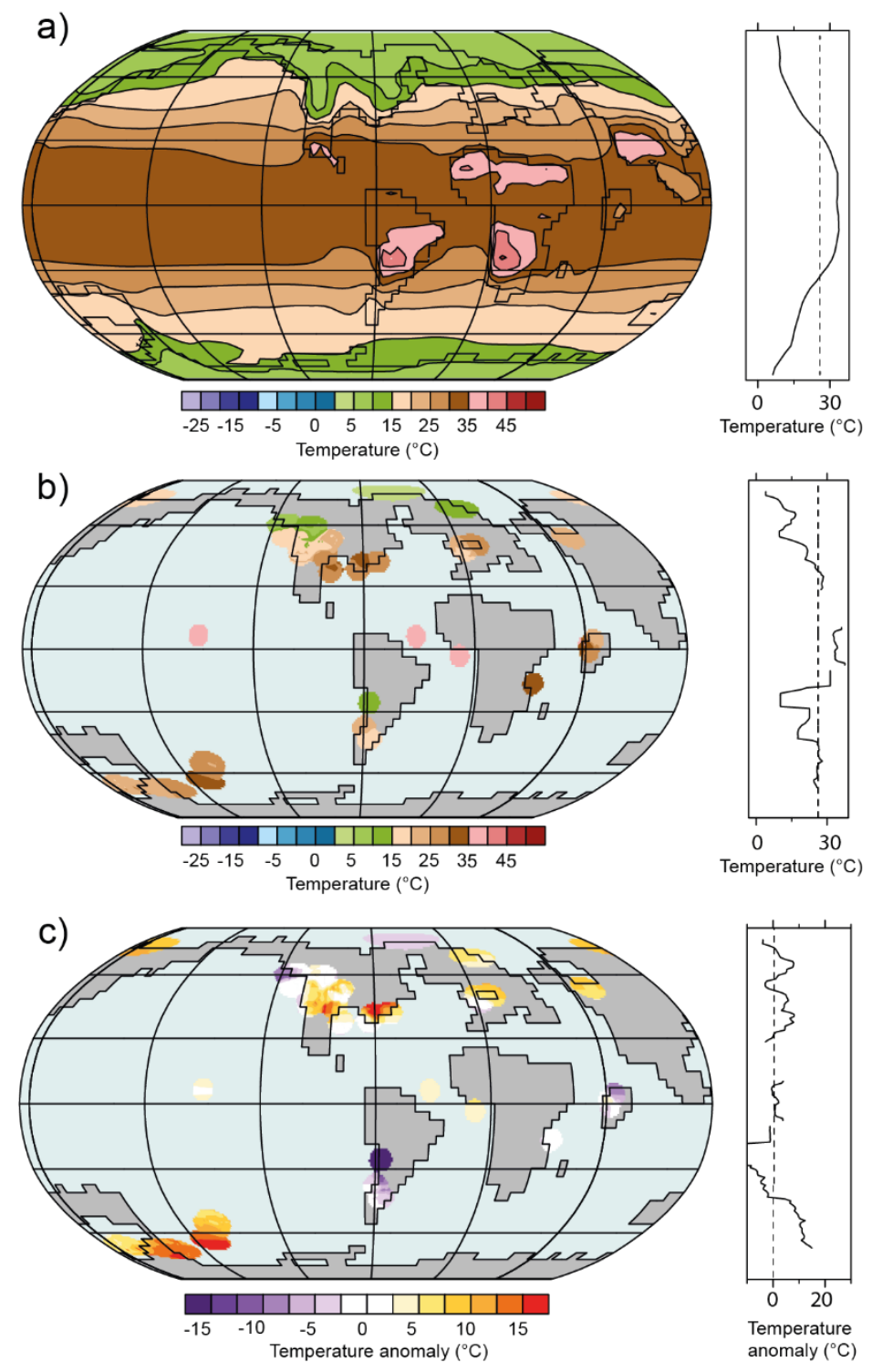

Figure 7: An illustration of Method $D_{\text {surf }} 1$ during the EECO. (a) Modelled early Eocene (2240 ppm) temperatures utilising CCSM3 (b) Interpolated absolute SST reconstructions, (c) Datamodel difference between (a) and (b). 


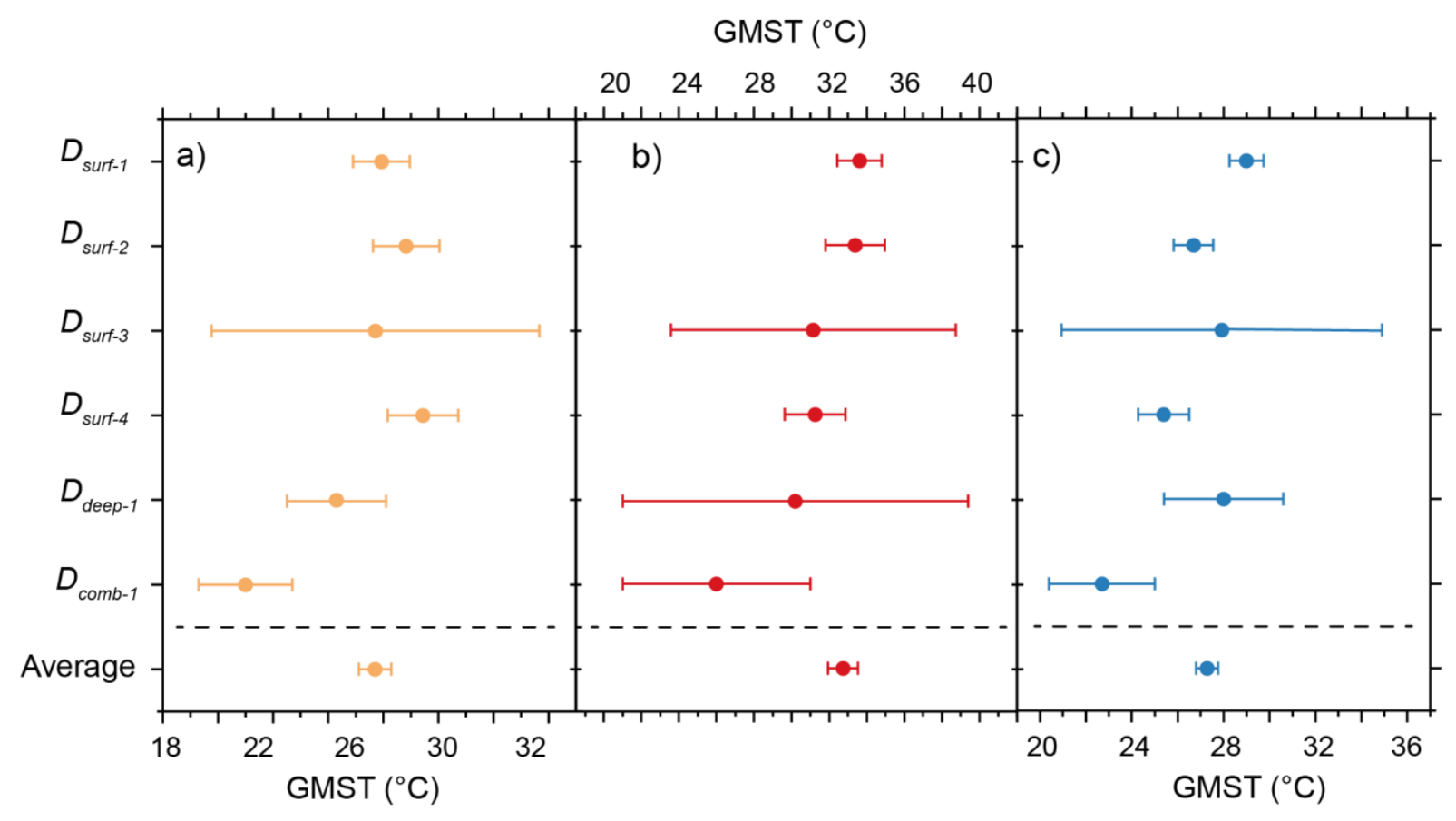

Figure 8: Summary of GMST estimates for the (a) latest Paleocene, (b) Paleocene-Eocene Thermal Maximum and (c) early Eocene Climatic Optimum. Error bars on each individual method are the standard deviation, except $D_{\text {surt }}-1$ and $D_{\text {surt }}-2$ which use the standard error. Error bar on weighted average is the reciprocal square root of the sum of all the individual weights. 


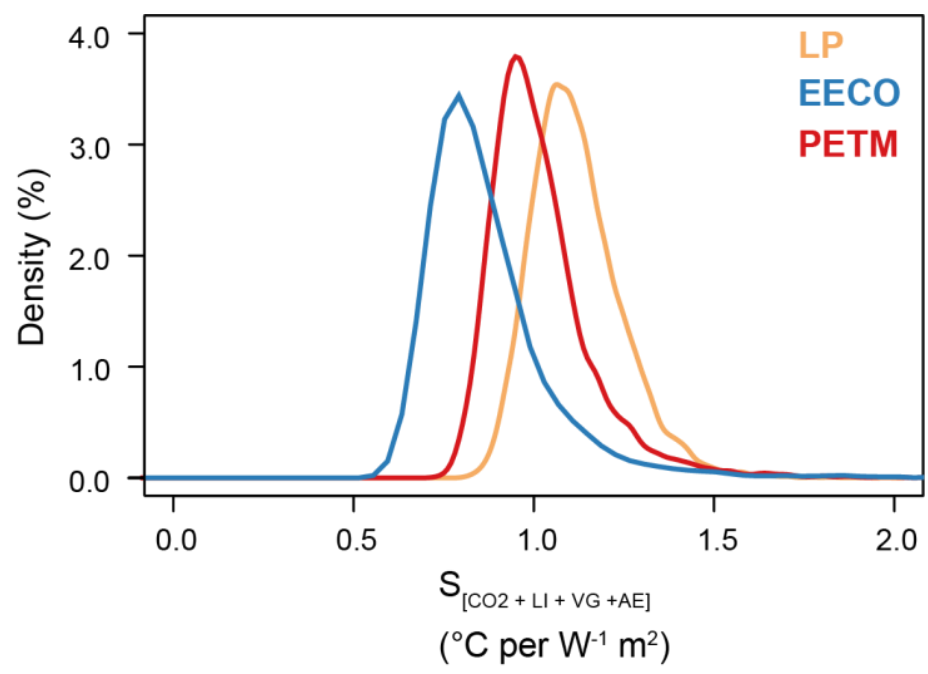

Figure 9: Probability density function of bulk ECS during the latest Paleocene, PETM and EECO that explicitly accounts for non- $\mathrm{CO}_{2}$ forcings of palaeography and solar constant, and feedbacks associated with land ice, vegetation, and aerosols (Zhu et al., 2019), i.e. $\mathrm{S}_{[\mathrm{CO}, \mathrm{LI}, \mathrm{VG}, \mathrm{AE}]}$ in the nomenclature of Rohling et al (2012). 